Saudi Journal of Medical and Pharmaceutical Sciences

Abbreviated Key Title: Saudi J Med Pharm Sci

ISSN 2413-4929 (Print) |ISSN 2413-4910 (Online)

Scholars Middle East Publishers, Dubai, United Arab Emirates

Journal homepage: https://saudijournals.com/sjmps

Original Research Article

\title{
Risk-Minimization Measures in the EU: Review of Two Year Period Safety Referral Procedures
}

\author{
Violeta Getova $^{1 *}$, Ilko Getov ${ }^{2}$ \\ ${ }^{1}$ Bulgarian Drug Agency, 8 Damyan Gruev str., 1303 Sofia, Bulgaria \\ ${ }^{2}$ Faculty of Pharmacy, Medical University-Sofia, 2 Dunav str., 1000 Sofia, Bulgaria
}

DOI: $10.36348 /$ sjmps.2020.v06i06.001

| Received: 30.05.2020 | Accepted: 08.06.2020 | Published: 14.06.2020

*Corresponding author: Violeta Getova

\section{Abstract}

The current study aims to research, systemize and analyze the qualitative characteristics of pharmacovigilance referral procedures which took place in the EU for two years period 2017-2018. For the purpose of the study PRAC decisions and minutes for all procedures which started and completed within 2017-2018 were extracted and systemized. The systemization was made based on several criteria including legal basis of procedure, scope, proposed risk-minimization measures. The results from the study showed that the PRAC's recommendations are most frequently focused on narrowing patient population and therapeutic indications and enhancing safety monitoring during medicines' use. National competent authorities play major role both as initiators of referrals and national safety monitors. The conducted analysis shows that conducting PRAC safety referral procedure is a complex and dynamic process where real-life clinical data is valuable source of information. The suggested risk-minimization steps are mainly focused on enforcement of measures already existing in the risk-management plan of the products. They also require a constant follow-up monitoring for efficacy. National competent authorities are leading participants in organizing the work and composing the agenda of the committee.

Keywords: pharmacovigilance, referral procedure, risk, drug safety, risk-minimization, PRAC.

Copyright @ 2020: This is an open-access article distributed under the terms of the Creative Commons Attribution license which permits unrestricted use, distribution, and reproduction in any medium for non-commercial use (NonCommercial, or CC-BY-NC) provided the original author and source are credited.

\section{INTRODUCTION}

Nowadays pharmaceutical legislation is recognized as one of the most synchronized amongst all members of the EU. Since 1995 the European Union has established a centralized structure - the European medicines agency (EMA) - responsible for the medicines used within its territory as well as the structure and regulation of pharmaceutical market. It is a scientific institution created in order to support the national competent authorities in their regulatory and surveillance work. EMA's main mission is protection of public health and promotion of rational medicines use for both human and veterinary needs [1]. It exercises its work via seven committees, each with a different area of expertise. The EU has a mechanism of granting a marketing authorization via a centralized procedure which is valid for all member states. In addition to that, the documents required for almost every regulatory procedure in the member states are identical: medicinal product dossier, clinical trials and substantial amendment application form, individual case safety report form etc. The legal harmonization between member states is the result of long lasting efforts of both national authorities and EU centralized structures. It is aimed at guaranteeing that all medicinal products who reach the market meet the community requirements for safety, efficacy and quality [2].

Safety of medicines is best described as the type, frequency and severity of the adverse drug reactions related to their use [3]. According to World Health Organization the definition of pharmacovigilance is the science and activities relating to the detection, assessment, understanding and prevention of adverse effects or any other drug-related problem [4]. It is not limited only to the adverse effects when used in authorized indications, dosage and population but also includes off-label use, misuse, and drug abuse. The main role of pharmacovigilance activities is assessment of safety after the medicine is placed on the market and continuous risk/benefit assessment. In the field of pharmacovigilance the most important step towards harmonization of legislation is taken in 2005 when the European Commission initiates an intense review of the current requirements for pharmacovigilance systems in the EU. The results from 
the review come in 2012 when series of changes are implemented in the European legislation. The previously existing documents Directive 2001/83 and Regulation 726/2004 are supplemented by Directive 2010/84/EC and Regulation 1235/2010, Regulation 1027/2012 and Directive 2012/26. These documents set the standards for pharmacovigilance activities, participants in PV system, role of institutions, legal requirements, PV inspections and information access, the way we know them today $[5,6]$. The Pharmacovigilance risk assessment committee (PRAC) of EMA is also created in 2012 as a continuation of the previously existing Pharmacovigilance Working Party. Its main role is providing expert opinion on safety of medicines authorized for use in the EU. Today it is the most important European structure in safety assessment of medicines as it is responsible for all aspects of riskmanagement: analysis and assessment of real-life data coming from spontaneous reporting of adverse drug reactions (ADR), risk/benefit assessment for new safety signals and conduction of referral procedures when necessary [7].

By the time of marketing authorization medicines have proved to be safe and effective based on clinical trials data. However, the main limitation we encounter is the fact that during clinical trials not all safety issues could present. This is due to the strict inclusion and exclusion criteria of the trials and the rather small number of patients involved in them [8]. Once the product is placed on the market it is accessible to much bigger and more heterogeneous population. This is why there is a great possibility that new and unknown safety issues could come up. According to EMA a safety signal is information on a new or known adverse event that may be caused by a medicine and requires further investigation [9, 10]. Information on safety signals can be extracted from a variety of sources such as studies and scientific literature but the most valuable source of safety information in pharmacovigilance is the spontaneous reporting of ADRs [11-14]. Since the creation of PRAC assessment of safety signals and referral procedures has been a major part of its activity. For the purpose of the study we focused on the safety procedures in a two-years period of time (2017-2018).

\section{Materials ANd Methods}

The current study aims to research, systemize and analyze the qualitative characteristics of pharmacovigilance referral procedures which took place in the EU in the period 2017-2018. In the analysis were included only those procedures which started and completed during the aforementioned period. For the purpose of the study PRAC decisions and minutes were extracted and systemized. The systemization was made based on the following criteria:

- Legal basis of procedure: art. 20 of Regulation $726 / 2004$ or art. 31 of Directive 2001/83
- Duration of procedure in months: based on decision for start of referral and final PRAC recommendation

- Scope of procedure: medicinal products or pharmacological class whose safety was studied

- Initiator: European Commission or National competent authority

- Proposed risk-minimization measures: education materials, change in product information, suspension of marketing authorization

\section{ReSUlTS AND DiscUSSION Legal Basis}

There are two types of safety referral procedures according to the legal ground for their conduction. Art. 20 of Regulation 726/2004 applies to medicinal product authorized via centralized marketing authorization procedure. In these cases, the European Commission, with or without national competent authorities opinion, can request from the EMA the conduction of a safety assessment procedure. The riskassessment committee of the EMA gives recommendation on the risk/benefit ratio of the products and transfers it to the CHMP - Committee for medicinal products for human use - to adopt EMA's final opinion. The CHMP can agree, modify or completely disagree with PRAC recommendations.

A referral procedure based on art. 31 of Directive 2001/83 could be initiated not only by the European Commission but as well as by any member state's competent authority or by marketing authorization holders. In the scope of this type of procedures are included medicinal products authorized via both centralized and decentralized procedures. Depending on the type of marketing authorization of the product subject of referral, PRAC recommendations are sent either to CHMP or to the CMDh - Coordination group for Mutual recognition and Decentralised procedures - human.

The results of both types of safety referral procedures could be no change to the condition of marketing authorization, alternations in it or a suspension of the marketing authorization. The recommendations are based on scientific and real-life data assessment of benefits and risks related to the use of the medicinal products. Generally, PRAC has 60 days to come up with recommendations and the $\mathrm{CHMP} / \mathrm{CMDh}$ has 30 days to make decision regardless whether the procedure was conducted according to the Regulation or the Directive. These time frames can be changed according with a case-by-case judgment.

In the scope of our research we identified a total of eight referral procedures which were started and completed in the period $1^{\text {st }}$ January $2017-31^{\text {st }}$ December 
Violeta Getova \& Ilko Getov; Saudi J Med Pharm Sci, June, 2020; 6(6): 429-434

2018 - half of them based on art. 20 of Regulation $726 / 2004$ and half of them based on art. 31 of Directive
2001/83. The referral of hydroxyethyl-starch (HES) is based on art. 107i of the same Directive (Table-1).

Table-1: Safety referral procedures in the EU 2017-2018 and their legal basis

\begin{tabular}{|l|l|l|l|}
\hline № & Procedures based on Directive 2001/83 & № & Procedures based on Regulation 726/2004 \\
\hline $\mathbf{1}$ & Quinolones \& fluoroquinolones & $\mathbf{1}$ & Zinbryta \\
\hline $\mathbf{2}$ & Valproate & $\mathbf{2}$ & Esmya \\
\hline $\mathbf{3}$ & Flupirtine & $\mathbf{3}$ & Xofigo \\
\hline $\mathbf{4}$ & HES $^{*}$ & $\mathbf{4}$ & Zinbryta \\
\hline
\end{tabular}

\section{Duration}

For the purpose of the study the period from decision for start of procedure until final PRAC recommendations were issued is considered as duration. The average duration of the referrals for the analyzed period is 8 months. The shortest procedure was 3 months long (second safety assessment of Zinbryta) and the longest one is the referral of quinolones and fluoroquinolones which was 20 months long (Fig-1).

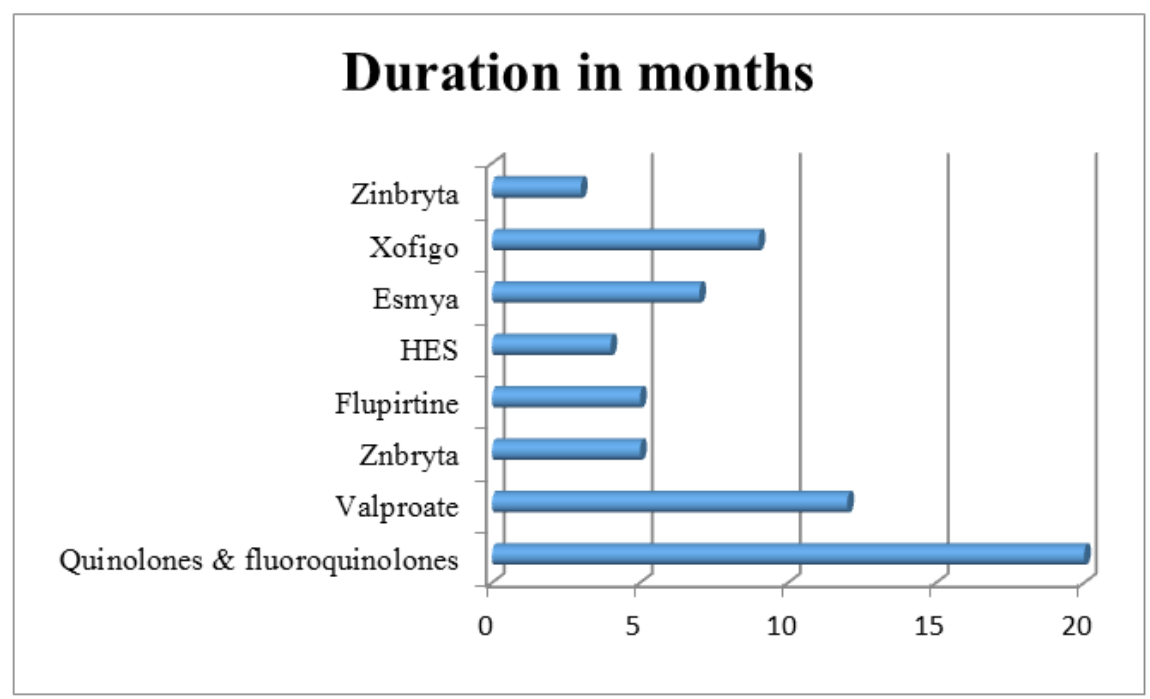

Fig-1: Duration of safety referrals in the EU 2017-2018

\section{Scope}

In the current study we analyzed the scope of the referral procedures as whether a concrete medicinal product or a whole pharmacological class was subject of assessment. It is quite noticeable that all the procedures according to the Regulation were related to a particular medicinal product: Zinbryta (daclizumab), Esmya (ulipristal acetate), Xofigo (Ra-223). This could easily be explained with the fact that the scope of art. 20 of Regulation 726/2004 include only medicinal products authorized via centralized procedure. Moreover, it is fair to say that centrally authorized products are usually of a more complex nature, with specific target population or medical condition. Novel products often present hope for people living with diseases without known cure and can receive marketing authorization faster. As pharmacovigilance primer purpose is continuous risk/benefit assessment after the product is placed on the market, the referral procedures for new medicines play significant role in broadening the knowledge on their safety profiles.

For the analyzed period, there were two risk assessment procedures for one biological medicinal product - Zinbryta - with indication multiple sclerosis. In June 2017 a main safety concern was the risk of developing unpredictable and potentially fatal immunemediated liver injury. By the end of the first referral PRAC concluded that the use of Zinbryta should be limited only to patients who do not have satisfying results from other therapeutic options and for whom no known alternative is recommended [15]. However, in 2018 after several reports of fatal encephalitis related to the use of Zinbryta, a second referral took place and in 3 months PRAC came to the conclusion that suspension of marketing authorization of Zinbryta is in patients' best interest [16].

Esmya (ulipristal acetate) is authorized for treatment of uterine fibroids in women who have not reached menopause. There were some cases where the use of Esmya has contributed to development of serious liver injury and this was the reason for starting a safety referral in 2017. At the same time started the safety assessment of prostate cancer medication Xofigo (Ra223) due to data suggesting that its use was related to decreased life duration and multiple fractures $[17,18]$. 
On the other hand, referrals according to art. 31 of Directive 2001/83 were usually investing the safety of a big number of medicinal products as they were focused on either a whole pharmacological class or an active substance that has been in use for a long time. Even though those medicinal products are widely used and considered well known, real-life data of safety surveillance often shows a significant risk of serious and potentially fatal ADRs. For several years now there have been a lot of questions regarding safety of valproate containing medicines. In the EU they are authorized under various trade names with main indication epilepsy. In a previous safety assessment in 2014 PRAC came to the conclusion that use of valproate in women of child-bearing potential and pregnant women poses a significant risk of malformation and development problems for the baby. It was then recommended that the use of valproate in women must be limited exclusively to cases where no known therapeutic alternative is suitable. In February 2017 the French competent authority initiated a novel review of valproate safety aimed at assessing the efficacy of the previously adopted risk-minimization measures. The review was concluded with the issue of various educational materials for pregnancy prevention in valproate-using patients [19].

The longest referral procedure for the analyzed period was of quinolones and fluoroquinolones. It was initiated in February 2017 and it took 20 months to be completed. One of the reasons for the length of procedure was surely the great number of products containing active substances from this pharmacological class. Moreover, in the EU there are plenty of different indications for their use. In PRAC's final recommendations some of them were deleted, others were changed. The marketing authorizations of a group of active substances were suspended [20]. PRAC has also recommended suspension of marketing authorization for solutions for infusion containing hydroxyethyl-starch after assessment in 2017. The committee has previously recommended restrictions in use of HES-containing solutions (referral in 2013) but several reports for fatal cases of sepsis in critically ill patients were the ground for their latest safety review. However, the CMDh did not agree with PRAC's recommendation as the suspension from the market might result in an unmet medical need [21].

Last but not least, for the analyzed period there was a safety referral of flipirtine-contatining medicines for pain relief authorized in some EU countries. Due to risk of serious live injury EMA's final decision in 2018 was suspension of the marketing authorization for these products. This was the only procedure in the period which did not have an impact in Bulgaria as there are no flupirtine-containing medicines authorized for use in our country.

\section{Initiator}

As previously mentioned the referral procedures based on Regulation 726/2004 could be initiated only by European Commission following request or recommendation by a national competent authority. Procedures based on Directive 2001/83 can be initiated either by a NCA, a marketing authorization holder or the EC. For the period subject of the current study, the European Commission has initiated only Regulation-based procedures and all other referrals were started due to national competent authorities' activity (Fig-2).

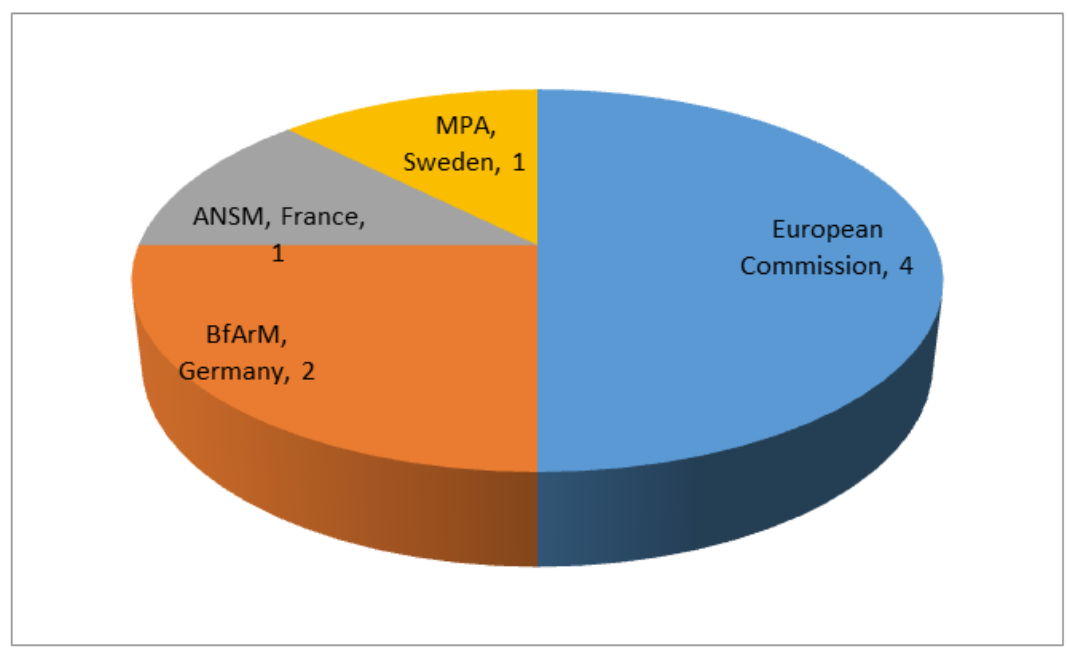

Fig-2: Initiators of safety referral procedures in the EU 2017-2018

This emphasizes the great value national pharmacovigilance systems have as they collect reports from everyday clinical practice from both healthcare specialists and patients. However, of all the EU countries, only three $(11 \%)$ competent authorities were initiators of safety referral which is a rather unsatisfying percentage (Table-2). 
Table-2: National competent authority activity in safety reviews in the EU 2017-2018

\begin{tabular}{|l|l|}
\hline Scope of referral & National competent authority initiator \\
\hline Quinolones \& fluoroquinolones & BfArM, Germany \\
\hline Valproate & ANSM, France \\
\hline Flupirtine & BfArM, Germany \\
\hline HES & MPA, Sweden \\
\hline
\end{tabular}

\section{Proposed Risk-Minimization Measures}

For the period subject to our study we can classify the risk-minimization measures proposed by PRAC and adopted by the EMA in three major categories:

- Restrictions in use

- Educational materials

- Suspension of marketing authorization
The most commonly proposed riskminimization measures concerned recommendations for indications and patient population. This type of decision was adopted in 3 out of 4 referral procedures of centrally authorized medicinal products. PRAC's recommendations were generally confirmed by the CHMP/CMDh with the exception of the HES referral where, as mentioned before, the EMA did not agree to suspend marketing authorization (Table-3).

Table-3: Referrals where $P R A C$ recommended restrictions in use

\begin{tabular}{|c|c|c|c|}
\hline Scope of referral & $\begin{array}{l}\text { Legal basis of } \\
\text { referral }\end{array}$ & PRAC recommendations & $\begin{array}{l}\text { Adopted } \\
\text { from EMA }\end{array}$ \\
\hline $\begin{array}{l}\text { Quinolones \& } \\
\text { fluoroquinolones }\end{array}$ & $\begin{array}{lr}\text { Art. } 31 & \text { Directive } \\
2001 / 83 & \end{array}$ & $\begin{array}{l}\text { Indications for use were reviewed and systemized in four } \\
\text { categories: } \\
\text { 1. Risk/benefit ratio is positive, without change } \\
\text { 2. Risk/benefit assessment shows need of restrictions of } \\
\text { use in these indications } \\
\text { 3. Risk/benefit ratio is negative, indications must be } \\
\text { deleted } \\
\text { 4. Indications are too broad, must be reworded and more } \\
\text { precise }\end{array}$ & Yes \\
\hline Zinbryta & $\begin{array}{l}\text { Art. } 20 \text { Regulation } \\
726 / 2004\end{array}$ & $\begin{array}{l}\text { Product to be used only in patients who do not have } \\
\text { satisfying therapeutic result from at least two other } \\
\text { treatments; liver monitoring during and up to } 6 \text { months after } \\
\text { stopping treatment }\end{array}$ & Yes \\
\hline HES & $\begin{array}{l}\text { Art. 107i Directive } \\
2001 / 83\end{array}$ & Suspension of marketing authorization & No \\
\hline Esmya & $\begin{array}{l}\text { Art. } 20 \text { Regulation } \\
726 / 2004\end{array}$ & $\begin{array}{l}\text { Product should not be used in women with known liver } \\
\text { problems; liver monitoring during and up to } 1 \text { month after } \\
\text { stopping treatment }\end{array}$ & Yes \\
\hline Xofigo & $\begin{array}{l}\text { Art. 20 Regulation } \\
726 / 2004\end{array}$ & $\begin{array}{l}\text { Product to be used only in patients who do not have } \\
\text { satisfying therapeutic result from at least two other } \\
\text { treatments and where no known alternative is acceptable; } \\
\text { fracture risk assessment before, during and after treatment }\end{array}$ & Yes \\
\hline
\end{tabular}

The safety review of valproate-containing medicines initiated by the French ANSM led to implementing a pregnancy prevention program in order to guarantee the use of contraception during treatment and conducting regular pregnancy tests. Furthermore, a special warning symbol must be placed on the package of valproate-containing medicines in order to raise patient awareness of the risks. A patient reminder card and updated educational materials are also included in PRAC's recommendations.

Two referrals (25\%) concluded with suspension of marketing authorization. One was the procedure initiated by BfArM to assess the risks of use of flupirtine-containing medicines. PRAC then concluded that the hazards outweigh the possible benefits of the treatment and products should be withdrawn from the market. CMDh agreed with PRAC and final EMA's decision was adopted. The other medicinal product which was linked to a negative benefit/risk ratio was Zinbryta. After the first referral and the proposed restrictions in use (Table-3), several reports for fatal encephalitis in March 2018 led to a second safety review and the final decision of suspension of marketing authorization for Zinbryta.

\section{CONCLUSION}

The conducted analysis of safety review procedures in the EU for two-years period show that both novel active substances as well as well-known and widely used pharmacological classes could be associated with new risks in the post-authorization 
period. The active surveillance and continuous benefit/risk assessment are key steps in a medicinal product life cycle. The real-life data from national pharmacovigilance systems is of great importance during the conduction of safety referrals, especially when it comes to products authorized via decentralized procedures. National competent authorities have the potential of initiating review of drug products safety on a European level which could lead to updated guidance adopted by all member-states.

\section{REFERENCES}

1. Permanand, G., Mossialos, E., \& McKee, M. (2006). Regulating medicines in Europe: the European Medicines Agency, marketing authorisation, transparency and pharmacovigilance, Clin Med (Lond), 6(1): 87-90.

2. Regulation $726 / 2004$. Regulation $726 / 2004$ of the European Parliament and of the Council of 31 March 2004 laying down Community procedures for the authorization and supervision of medicinal products for human and veterinary use and establishing a European Medicines Agency. 2004, available at http://eurlex.europa.eu/LexUriServ/LexUriServ.do?uri=OJ: L:2004:136:0001:0033:en:PDF.

3. Corbet, B. (2007). Manual of drug safety and pharmacovigilance. Johns and Nartlett publishers.

4. WHO. (2002). The importance of pharmacovigilance. Safety monitoring of medicinal products.

5. Farcaş, A., Măhălean, A., Bulik, N. B., Leucuta, D., \& Mogoșan, C. (2018). New safety signals assessed by the Pharmacovigilance Risk Assessment Committee at EU level in 20142017. Expert review of clinical pharmacology, 11(10), 1045-1051.

6. Borg, J. J., Aislaitner, G., Pirozynski, M., \& Mifsud, S. (2011). Strengthening and rationalizing pharmacovigilance in the EU: where is Europe heading to?. Drug safety, 34(3), 187-197.

7. EMA. PRAC: Rules of procedure, EMA/PRAC/567515/2012 Rev. 2, 14 April 2020 available https://www.ema.europa.eu/en/documents/other/pr ac-rules-procedure_en.pdf.

8. Pirmohamed, M., Atuah, K. N., Dodoo, A. N., \& Winstanley, P. (2007). Pharmacovigilance in developing countries.

9. Uppsala monitoring centre, Research and Scientific Development, https://www.whoumc.org/research-scientific-development/signaldetection/signal/.

10. EMA. Guideline on Good Pharmacovigilance Practice (GVP) - Module IX - Signal Management. EMA/827661/2011 Rev 1 available at

https://www.ema.europa.eu/en/documents/scientifi c-guideline/guideline-good-pharmacovigilancepractices-gvp-module-ix-signal-management-rev1_en.pdf.

11. World Alliance for Patient Safety. (2005). WHO Draft Guidelines for Adverse Event Reporting and Learning Systems. Geneva: World Health Organization (WHO/EIP/SPO/QPS/05.3).

12. Health on the net foundation, http://www.hon.ch/Global/pdf/TrustworthyOct200 6.pdf.

13. Mann's Pharmacovigilance $3^{\text {rd }}$ edition (2014) edited by Andrews E. \& Moore N., Wiley Blackwell.

14. Patadia, V. K., Coloma, P., Schuemie, M. J., Herings, R., Gini, R., Mazzaglia, G., ... \& Sturkenboom, M. (2015). Using real-world healthcare data for pharmacovigilance signal detection-the experience of the EU-ADR project. Expert review of clinical pharmacology, 8(1), 95-102.

15. PRAC Assessment Report 31 October 2017 available https://www.ema.europa.eu/en/documents/referral/ zinbryta-article-20-referral-prac-assessmentreport_en.pdf.

16. PRAC Assessment Report 17 May 2018 available at

https://www.ema.europa.eu/en/documents/referral/ zinbryta-article-20-referral-prac-assessmentreport_en-0.pdf.

17. EMA. Assessment report on provisional measures 08 February 2018 available at https://www.ema.europa.eu/en/documents/referral/ esmya-article-20-procedure-assessment-reportprovisional-measures_en.pdf.

18. EMA. PRAC Assessment report available at https://www.ema.europa.eu/en/documents/referral/ xofigo-article-20-procedure-prac-assessmentreport_en.pdf.

19. EMA. PRAC Recommendations 9 February 2018 available https://www.ema.europa.eu/en/documents/referral/ valproate-article-31-referral-prac-recommendsnew-measures-avoid-valproate-exposurepregnancy_en.pdf.

20. EMA. PRAC Assessment report 16 October 2018 available at https://www.ema.europa.eu/en/documents/referral/ quinolone-fluoroquinolone-article-31-referralassessment-report_en.pdf.

21. EMA. CMDh Recommendations available at https://www.ema.europa.eu/en/documents/pressrelease/hydroxyethyl-starch-solutions-cmdhintroduces-new-measures-protect-patients_en.pdf 